\title{
EL PRINCIPIO GENERAL DEL DERECHO DE CONFIANZA LEGÍTIMA
}

\author{
The principle of legitimate expectations
}

Jaime RODRÍGUEZ-ARANA

Sumario:

I. Introducción. II. Principios generales y derecho administrativo. III. Etica, valores, principios generales y derechos fundamentales. IV. El principio de la buena administracion y sus corolarios. $V$. El principio de buena fe, el principio de seguridad jurídica y el de confianza legítima. VI. Reflexion conclusiva. Bibliografia

Resumen. En el marco de los principios de una buena administración pública destacan, entre otros, los de seguridad jurídica, buena fé y confianza legítima. En concreto este principio significa que las expectativas que la Administración pública ha generado con sus actuaciones deben ser respetadas en el futuro de acuerdo con los principios de congruencia y coherencia salvo que se justifique en concreto, con argumentos razonables, la necesidad de proceder de otra forma.

Palabras clave: Principios generales del derecho. Administración Pública. Derecho Administrativo. Jurisprudencia.

Abstract. Amongst the principles governing good public administration three of the most noteworthy are those of legal certainty, good faith and legitimate expectations. More specifically, the last of these implies that the expectations generated by a public administration through its actions should be respected in the future, in accordance with the principles of consistency and coherence, unless the need to act otherwise can be specifically justified on the basis of reasonable arguments.

Key words. General principles oflaw. Public administration. Administrative law. Jurisprudence.

\section{INTRODUCCION}

El estudio de los principios generales del Derecho en el campo del Derecho Administrativo puede realizarse de muy diferentes formas, atendiendo a distintos puntos de vista. Se puede, por ejemplo, analizar su condición de fuente del Derecho y explicar cuales son sus peculiaridades proyectadas sobre nuestra disciplina. Es posible, también, estudiar específicamente su carácter de elemento informador y transversal de todo el Ordenamiento jurídico-administrativo. Igualmente, se puede subrayar desde su conexión a la dimensión ética hasta su incidencia sobre el plano de los valores. Además, nos podemos situar a partir del análisis de los principios políticos que presiden el Estado social y democrático de Derecho o centrarse

\footnotetext{
${ }^{1}$ Presidente del Foro Iberoamericano de Derecho Administrativo. Catedrático de Derecho Administrativo de la Universidad de La Coruña (ESPAÑA)
} 
en el estudio de los aforismos, de las técnicas de argumentación, de las reglas de interpretación o de determinados criterios procesales. Es decir, como señala Santamaría Pastor, existe una pluralidad de significados y de aproximaciones en relación con los principios generales que hacen necesario clarificar y concretar el objeto de la reflexión.

Si bien es cierto que la doctrina con frecuencia utiliza la expresión principios generales del Derecho para referirse a una pluralidad de expresiones, en mi opinión los principios generales son principios que hacen presente y operativa la idea de justicia. Son, como su propio nombre indica, previos a la norma, coetáneos a ella y elementos que facilitan la interpretación de la norma con arreglo a los parámetros de la justicia, del Estado de Derecho, que como decía KLEIN es en esencia un Estado de justicia.

En un mundo de hipertrofia normativa, en un mundo en el que las normas jurídicas no es que sean un dechado de perfección técnica, en un mundo el que existe una relativa dictadura del positivismo, es menester volver a pensar en el sentido y la función del Derecho, en el sentido y la función del Derecho Administrativo entendido, como diría González Navarro, como el Derecho del poder público para la libertad solidaria. Pues bien, las reflexiones que siguen, elaboradas para subrayar la importancia del principio de confianza legítima en el moderno Derecho Administrativo global, parten de este convencimiento: gracias a los principios generales el Derecho sigue siendo Derecho. Quiero con ello decir simplemente que frente a la tentación, no siempre resistida, de convertir al Derecho Administrativo en una herramienta o instrumento del poder público o económico, la encarnación principal de la justicia en los principios nos permite seguir alimentando la esperanza de que el Derecho Administrativo sigua siendo el dique de contención, por una parte, del poder incontrolado, del poder irracional, del poder que se sale de los cánones de la moderación y la templanza en cuyo marco se debe ejercer el poder en un Estado de Derecho. Por otra parte, los principios generales permiten, desde una perspectiva positiva, configurar un Derecho Administrativo en el que las instituciones, categorías y conceptos reflejen la racionalidad y el sentido de servicio objetivo al interés general que de ellos se espera.

En las páginas que siguen, el lector va a encontrar una serie de comentarios y meditaciones sobre la relevancia del principio de confianza legítima en el Derecho Administrativo desde el examen de la última jurisprudencia contencioso administrativa en España. Así se ha operado porque quien escribe es partidario desde hace tiempo de modular y contrastar la teoría con la jurisprudencia. Es más, tantas veces la teoría surge de la jurisprudencia como bien sabemos. En el caso presente, además, la jurisprudencia nos ayuda a no perder de vista el sentido que entre nosotros tiene el sometimiento pleno, como dispone el artículo 103 de la Constitución española, de la Administración pública al Derecho. Sujeción que, en buena medida, se produce gracias a la existencia de una serie de principios que proyectan su luz para ver los problemas en su real y justa dimensión y que son la atmósfera en la que ha de respirar el Ordenamiento jurídico administrativo. La jurisprudencia, como veremos enseguida, enseña que los principios generales son el resultado del genio jurídico de la construcción del Estado de Derecho y la esencia del entero Ordenamiento jurídico.

En el marco del Derecho Administrativo los principios generales, además de ser fuente en defecto de ley o costumbre, constituyen, como señala con carácter general el Código Civil, criterios inspiradores del sistema normativo de nuestra disciplina. De este modo, los principios generales, que son la esencia del Ordenamiento, siempre nos ayudarán a realizar esa fundamental tarea de asegurar y garantizar que el poder público en todo momento se mueve y actúa en el marco del Derecho. Es más, su carácter inspirador del Ordenamiento nos lleva 
a reconocer en los principios las guías, los faros, los puntos de referencia necesarios para que, en efecto, el Derecho Administrativo no se convierta en una maquinaria normativa al servicio del poder de turno sin más asideros que las normas escritas y las costumbres que puedan ser de aplicación en su defecto.

Vamos a estudiar, por tanto, algunos de los pronunciamientos de la jurisprudencia contencioso administrativa española acerca de esta capital cuestión. Analizaremos también, junto a las conexiones entre principios, ética y valores, la centralidad de la dignidad del ser humano en su relación con los principios y, más en concreto, el principio de buena fe y el principio de seguridad jurídica en relación con el de confianza legítima, objeto, éste último de estas líneas.

\section{PRINCIPIOS GENERALES Y DERECHO ADMINISTRATIVO.}

En los inicios del siglo XXI la pregunta acerca de la significación de los principios generales del Derecho en el Derecho Administrativo puede ser contestada desde dos planteamientos muy distintos. Desde el positivismo cerrado se diría que los principios generales no tienen apenas más sentido que el de, en todo caso, reconocer en términos abstractos las reglas que se expresan en el sistema normativo. El sistema normativo se da a si mismo los principios porque es el Ordenamiento el origen y la causa de ellos. Si, por el contrario, nos situamos en una perspectiva de positivismo abierto, de positivismo que reconoce la existencia de un solar jurídico general, de una cultura jurídica universal que representa el Estado de Derecho, entonces las cosas son de otra manera. Desde esta perspectiva, los principios generales juegan un papel central porque son los garantes de que el Estado de Derecho y sus postulados sean una realidad en todas las ramas del Derecho. Así, de esta manera, los principios no son solo fuente del Derecho, que no es poco, sino que como constata el Código Civil, son elementos inspiradores, criterios sobre los que se debe edificar el Derecho Administrativo. Claro, si el Derecho Administrativo no es más que una rama del Público que regula relaciones jurídicas entre la Administración y los ciudadanos sin más, los principios tendrán una funcionalidad muy limitada. Si el Derecho Administrativo se concibe como el Derecho del poder para la libertad del ser humano, entonces encaja perfectamente la doctrina que la propia jurisprudencia española ha confeccionado sobre el sentido y misión de los principios generales del Derecho en el Derecho Administrativo.

A este propósito debe tenerse presente que el Tribunal Supremo español señaló por sentencia de 18 de febrero de 1992 que "los principios generales del Derecho, esencia del Ordenamiento jurídico, son la atmósfera en que se desarrolla la vida jurídica, el oxígeno que respiran las normas, lo que explica que tales principios informen las normas - art. 1.4 del Código Civil- y que la Administración esté sometida no sólo a la ley sino también al Derecho - art. 103 de la Constitución-. Y es claro que si es principios inspiran la norma habilitante que atribuye una potestad a la Administración, esta potestad ha de actuarse conforme a las exigencias de los principios".

A poco que se examine en sus justos términos la doctrina que se contiene en esta sentencia se comprenderá el alcance y significado de los principios generales como exponentes del solar jurídico, del ambiente general que ha de presidir el entero sistema normativo. Se trata, en este caso, de los principios como elementos basilares del Ordenamiento, como las columnas vertebrales que sostienen y dan vida a las normas jurídicas. Con palabras de la sentencia del Tribunal Supremo, son el oxígeno que envuelve a las normas, la atmósfera que 
permite la pervivencia de las normas. Si se desconocen o si se eliminan es como si dejara de existir el oxígeno para el hombre. Por eso, los principios generales, desde esta perspectiva de elementos informadores y de criterios esenciales, han de ser tenidos muy en cuenta no sólo por el intérprete de la norma, sino también por quien la elabora. En el caso del principio de confianza legítima, como veremos, su existencia impide la generación o cristalización de situaciones de situaciones arbitrarias, irracionales, que puedan socavar el ambiente que debe presidir las relaciones jurídicas entre Administración y ciudadanos.

Es verdad que muchos principios han venido al mundo jurídico como consecuencia del trabajo de la doctrina y la jurisprudencia. En otros casos, además, aparecen, como no pude ser menos, reflejados en las normas. Pero lo más importante es que existen por si mismos porque son la proyección en la realidad jurídica de la esencial idea de justicia que trasciende al Ordenamiento y le da sentido. Desde este punto de vista, los principios son previos al Ordenamiento. Podría decirse que son su fundamento y que el Ordenamiento se justifica en la medida en que dichos principios inspiran y presiden el sistema normativo. Como es sabido, la recepción en España en 1999, en la reforma de la ley de régimen jurídico de las Administraciones públicas y del procedimiento administrativo común, procede de la propia jurisprudencia del Tribunal de Justicia de las Comunidades Europeas, como confiesa la propia exposición de motivos de tal reforma.

Esta idea, realmente gráfica y estimulante, de que los principios son la atmósfera y el oxígeno de las normas pienso que explica hasta que punto el olvido de los principios precipita la degradación del Derecho. En efecto, hoy en día, sin ser demasiado pesimista, más bien realista, podemos afirmar sin temor a equivocarnos que frente al intento, sistemático y pertinaz, de convertir el Derecho Administrativo en un mero apéndice del poder, los principios generales se levantan como valladar inexpugnable que permite evitar esta terrible operación. Antes bien, el Derecho Administrativo del Estado de Derecho debe mucho a los principios generales. Tanto que si no fuera por ellos, probablemente la lucha contra las inmunidades del poder de la que habla García de Enterría hubiera sido desigual y con un claro vencedor.

Reducir los principios generales a los que contenga la norma escrita por excelencia como es la Constitución, es degradarlos a la condición de elementos auxiliares o adjetivos de la norma escrita, algo que en modo alguno es coherente con la naturaleza de elemento esencial del Ordenamiento que el propio Tribunal Supremo afirma categóricamente, por ejemplo, en la sentencia de 16 de mayo de 1990, cuando entiende que éstos son "esencia del Ordenamiento jurídico, la atmósfera en la que se desarrolla la vida jurídica”. Si son la esencia, entonces han de impregnar todo el Ordenamiento y, por ello, su aplicación será directa.

Conviene llamar la atención acerca de que el Tribunal Supremo, cuando ha ido construyendo la teoría del control de la discrecionalidad administrativa a través de los principios generales, ha conectado la existencia de dichos controles al genio expansivo del Estado de Derecho (sentencia de 8 de octubre de 1990). Efectivamente, el Estado de Derecho es un Estado de justicia, es un Estado en que el poder ha de actuar conforme a patrones y cánones formales y sustanciales. Si nos quedamos únicamente en la vertiente procedimental y formal del poder resulta evidente que éste puede terminar, ejemplos hay y lacerantes de todos conocidos, siendo la principal y más efectiva terminal del autoritarismo y la ausencia de medida. Por eso, la existencia de controles sustanciales viene determinada por los principios, que son, como vuelve a recordar esta sentencia, la atmósfera en que se desarrolla la vida jurídica, el oxígeno que respiran las normas. 
Parece fuera de dudas que existen una serie de principios de Derecho, corolarios necesarios de la cultura jurídica inspirada en el Estado de Derecho que son precisamente las garantías de que el sistema normativo camina por la senda adecuada. En nuestro caso: que existen una serie de principios generales, entre los que se encuentran el de seguridad jurídica, el de interdicción de la arbitrariedad o, entre otros, el de confianza legítima, que garantizan que la actuación administrativa sea ejercicio real de servicio objetivo al interés general.

Desde este ángulo, atendiendo a la capitalidad de los principios de Derecho, podemos señalar que estos criterios jurídicos, que son fundantes e inspiradores del Ordenamiento, constituyen también el solar y el "humus" que aseguran la orientación del sistema normativo hacia la justicia, algo que el superado positivismo jurídico, nunca pudo resolver por obvias razones, especialmente porque de la teoría inmanente del Ordenamiento no surge más que pensamiento estático y unilateral.

Ha sido Santamaría Pastor quien ha llamado la atención sobre la relevancia que los principios generales del Derecho juegan en el Derecho Administrativo. Realmente, si es verdad que el juego de éstos es mayor en los Ordenamientos más jóvenes, puesto que no han tenido tiempo suficiente para una labor de maduración jurídica que permita recogerlos en el Derecho escrito, entonces en el Derecho Administrativo, ciertamente, los principios generales del Derecho tienen reservado un lugar de privilegio. Si convenimos en que llevamos un poco más de dos siglos de Derecho Administrativo entonces estaremos de acuerdo en que, efectivamente, en nuestra disciplina los principios son esenciales. Es más, si también acordamos que el Derecho Administrativo, como dice Santamaría Pastor, nace de los comentarios que hace la doctrina a las resoluciones del Consejo de Estado francés, entonces no tendremos más remedio que concluir que el Derecho Administrativo es una elaboración operada casi exclusivamente a partir de principios generales, en torno a los cuales ha ido cerrándose una tupida y extensa red de principios y reglas secundarias que han terminado por formar un sistema. Como sentencia solemnemente este profesor, han sido los principios generales, más que las normas escritas, las paredes maestras en torno a las cuales se ha ido levantando el edificio del régimen jurídico de las Administraciones públicas. Edificio que tiene en la base, en los pilares, los postulados del Estado de Derecho que, como es bien sabido, han precipitado en un conjunto de principios generales que son los que marcan el rumbo a toda Administración que pretenda cumplir con su función constitucional de servicio objetivo a los intereses generales. El Derecho Administrativo bien podría decirse que nace de la mano de un conjunto de principios que hacen de él un Derecho diseñado para que el poder publico se ejerza de acuerdo con el Estado de Derecho.

Hoy, doscientos años después, la realidad normativa ha superado cualquier previsión en lo que a cantidad, y calidad, se refiere. Estamos invadidos por toda clase de normas, estamos inundados de normas para todo y por todo. Es el reino de la hiperactividad normativa en el que es menester, como también señala Santamaría Pastor, aferrarse a los asideros seguros desde los que se pueda mantener el destino de la nave del Derecho Administrativo hacia puerto seguro. Pues bien, el timón del sistema normativo del Derecho Administrativo, hoy más que nunca, debe estar bien orientado hacia esos principios generales del Derecho que he denominado fundamentales. 
III ETICA, VALORES Y PRINCIPIOS GENERALES DEL DERECHO.

El artículo 1.1 de la Constitución española de 1978 dispone que España es un Estado social y democrático de Derecho, que propugna como valores superiores de su Ordenamiento jurídico la libertad, la justicia, la igualdad y el pluralismo político. Este precepto, como bien sabemos, expresa los principios centrales que presiden el régimen jurídico-político constitucional. Son, por ello, los vectores y postulados generales sobre los que se asienta la cultura jurídica universal que trae causa del Estado social y democrático de Derecho, que es el modelo constitucional de Estado en que hoy toma forma el denominado Estado de Derecho. En efecto, los principios de libertad, justicia, igualdad y pluralismo traen causa de la cláusula del Estado social y de democrático de Derecho. Tal cláusula engloba las del Estado de Derecho, del Estado social y del Estado democrático. Es decir, los principios de legalidad, reconocimiento de los derechos fundamentales, separación de poderes, solidaridad y participación son principios rectores del Ordena jurídico, social y económico. De ellos, además, se derivan, de acuerdo con el artículo 9 de la Constitución, los principios de sujeción de los ciudadanos y los poderes públicos a la Constitución y al resto del Ordenamiento jurídico, de jerarquía normativa, de publicidad de las normas, de irretroactividad de las disposiciones sancionadoras no favorables o restrictivas de derechos individuales, de seguridad jurídica, de responsabilidad y de interdicción de la arbitrariedad de los poderes públicos.

En el artículo 1 de nuestra Ley Fundamental se encuentran los valores superiores del Ordenamiento jurídico, valores que, como su propio nombre indica, discurren en el mundo de la ética, de la axiología que, a su vez, desencadena los principios del artículo 9.3, unos fundamentales y otros derivados. Los valores superiores, que son también principios, en este caso fundamentales, constituyen corolarios necesarios de la idea de Estado social y democrático de Derecho. Son, insisto, los principios generales del Derecho fundamentales: principio democrático, principio de centralidad de la dignidad del ser humano, principio de participación, principio de libertad, principio de igualdad, principio de justicia, principio de participación, principio de solidaridad, principio de pluralismo, principio de seguridad y principio de interdicción de la arbitrariedad de los poderes públicos. Estos principios, en el plano del Derecho Administrativo, dan lugar, a su vez, a otros que también siguen siendo centrales en la materia. Tales serían el principio de buena fe, el principio de racionalidad, el principio de objetividad, el principio de la buena Administración, el principio de sometimiento de la Administración a la ley al Derecho o el principio de confianza legítima entre otros.

Llegados a este punto, podríamos cuestionarnos acerca de la relación entre Etica,, Moral y Derecho, tema de gran e indudable interés académico que, además, incide de manera sobresaliente sobre la realidad. Mucho se ha debatido sobre la cuestión y no es del caso intentar siquiera una breve exposición esquemática de las distintas opiniones y tesis manifestadas a lo largo del tiempo. Parece razonable que me limite a lo que pueda tener una relación más directa e inmediata con el tema asignado. En ese sentido, convendría centrarse en la realidad constitucional española tal y como venimos haciendo sin perder de vista que por encima y por debajo de la Norma de las Normas existen principios, parámetros generales que como precipitados de la cultura jurídica universal del Estado moderno constituyen señales indelebles de la aspiración a la justicia que ha de caracterizar el funcionamiento y la actuación de todos los poderes públicos sin excepción. Entre ellos, los derechos fundamentales de la persona ocupan un lugar bien destacado. 
La relación entre Etica y Derecho, para el tema que nos ocupa, ha sido analizada por el propio Tribunal Supremo español en la sentencia de 13 de julio de 1982. Los valores superiores del Ordenamiento jurídico discurren por la senda de lo que podríamos denominar Etica jurídica, de forma y manera que el solar ético es bien importante en materia de Derecho Administrativo, no sólo porque obviamente el ejercicio del poder público haya de conducirse por estos derroteros, sino porque la permanencia de los valores superiores es la garantía de que el Ordenamiento jurídico en su conjunto se inspire en los que hemos llamado principios generales fundamentales.

En efecto, la sentencia citada señala que las invocaciones a la Etica y a la Moral son merecedoras del máximo respeto "puesto que nunca es más noble la función de los Tribunales que cuándo ésta se desarrolla aplicando el derecho sobre bases éticas, ya que existe una Etica jurídica, que no es, ni más ni menos, que una sublimación del Derecho”. El Tribunal Supremo, además, entiende que la Etica no es fuente del Derecho, sino un "simple estímulo vigorizante de la aplicación de éste”.

El Tribunal Supremo español entiende, pues, que el Derecho ha de moverse sobre un suelo sólido y firme, que no es otro que el de la Etica, Etica jurídica que, en la materia que nos ocupa en el día de hoy, se encuentra representada por los principios generales del Derecho de carácter fundamental. La mayor parte, como hemos indicado, están establecidos en la Constitución y responden al nombre de valores superiores del Ordenamiento jurídico. Además, la Ética, que no es fuente del Derecho, es elemento vigorizador, vivificador, robustecedor del Derecho. Los principios generales del Derecho, por tanto, son la atmósfera que preside la vida de las normas, el oxígeno que respiran, el solar por el que se mueven y un estimulo que las vigoriza y las fortalece en todo momento. Si renunciamos, pues, a los principios generales del Derecho condenamos a las normas a su degradación y perversión, algo que hoy está bastante de actualidad al haber vencido una idea utilitaria, de uso alternativo, que pone al servicio del poder las normas y los principios y no al revés. En este sentido, el principio de confianza legítima es manifestación del valor superior de la seguridad y de la racionalidad o, en sentido negativo, de la prohibición de la arbitrariedad y de la proscripción de la incerteza, de la imprevisibilidad o de la inseguridad jurídica.

\section{EL PRINCIPIO DE BUENA ADMINISTRACION Y SUS COROLARIOS.}

Tras la aprobación de la Carta Europea de los Derechos fundamentales en el año 200o, el 6 de diciembre, contamos con un nuevo derecho fundamental en el espacio europeo: el derecho a la buena Administración pública. Derecho que también tiene una dimensión de principio. Es más, probablemente su formulación como derecho fundamental se produce tras haber comprobado la trascendencia de un principio general del Derecho tan relevante como el de la prohibición de la arbitrariedad en su vertiente positiva. El principio de interdicción de la arbitrariedad, con reflejo constitucional en el artículo 9.3 de la Constitución, ofrece una perspectiva en positivo que es el principio de racionalidad o el principio de objetividad, principios que tienen en el campo del Derecho Administrativo una trascendencia indudable. Corolario de estos principios es el de confianza legítima en la medida en que la actuación de la Administración ha de ser coherente con los precedentes y también con las expectativas que genera de acuerdo con los principios de certeza, previsibilidad y seguridad jurídica. Es decir, una buena Administración es una Administración racional, o lo que es lo mismo, coherente con el servicio objetivo al interés general que funda toda su actuación. 
El principio de racionalidad, objetividad o congruencia con el interés general adquiere una significación especial cuando se trata del ejercicio de potestades o poderes administrativos calificados de exorbitantes o extraordinarios. En estos casos en los que se operan auténticos poderes discrecionales es más importante, si cabe, la exigencia de objetividad. El Tribunal Supremo ha llegado a afirmar, en sentencia de 2 de noviembre de 1991, que la Administración, en este caso la local, que disfruta de potestades y prerrogativas está obligada, por ellos mismo, a "seguir una conducta de ejemplaridad y de buena fe". Principio de buena fe que, como sabemos, está en la base del principio de confianza legítima que se puede entender como la vertiente de la buena fe examinada desde el lado de la Administración pública.

V. EL PRINCIPIO DE BUENA FE, EL PRINCIPIO DE SEGURIDAD JURIDICA Y EL PRINCIPIO DE CONFIANZA LEGÍTIMA

En efecto, el principio de buena fe es uno de los principios generales del derecho más estudiados porque plantea el alcance y los límites de las conductas que son propias a los sujetos en las relaciones jurídicas, sean éstas públicas o privadas. En el caso del Derecho Público, la exigencia de la buena fe se entiende bien precisamente por la naturaleza de los poderes que ejerce la Administración y por su especial misión de servicio objetivo al interés general. Efectivamente, no es posible comprender un servicio objetivo al interés general si no es de acuerdo con la buena fe. Buena fe que, además, como ya adelantamos, el legislador español introdujo en el año 1999 en la reforma que entonces se hizo de la ley de régimen jurídico de las Administraciones públicas y del procedimiento administrativo común y que a mí me tocó el honor de dirigir desde el ministerio de las Administraciones públicas de entonces. El hoy artículo 3.1 "in fine” señala que las Administraciones públicas deben respetar en su actuación los principios de buena fe y confianza legítima.

La jurisprudencia del Tribunal Supremo español es bien clara en la materia, habiendo declarado por sentencia de 18 de febrero de 1992 que uno de "los principios que informan el Ordenamiento jurídico es el de que los derechos deberán ejercitarse conforme a las exigencias de la buena fe, artículo 7.1 del título preliminar del Código Civil”, principio que se infringe, como dice la sentencia del Tribunal Supremo de 29 de enero de 1965, cuando se finge ignorar lo que sabe (...), se realiza un acto equívoco para beneficiarse intencionadamente de su dudosa significación, o se crea una apariencia jurídica para contradecirla después en perjuicio de quien puesto su confianza en ella. La jurisprudencia contencioso-administrativa ha venido haciendo frecuente uso de este principio general, en campos distintos como el de las notificaciones, los contratos administrativos, la expropiación forzosa...declarando que el principio de la buena fe es inspirador tanto para los actos de la Administración como para los actos del administrado (sentencia de la sala cuarta de 23 de enero de 1976). Esta sentencia pone de manifiesto dos cuestiones que conviene subrayar, siquiera sea brevemente. Veamos.

La primera se refiere a que los principios generales del Derecho son la atmósfera en la que viven y se desarrollan las normas jurídicas, sean del mundo del Derecho Privado, sean del mundo del Derecho Público. La unidad del Derecho y las exigencias de que la justicia resplandezca en el Ordenamiento jurídico en su conjunto explican que para el Derecho Administrativo los principios generales adopten expresiones adecuadas a su propia naturaleza pero vinculados a la idea de la justicia. En este sentido, hay principios que presiden las actuaciones de los sujetos de la relación jurídica, sea esta pública o privada. Uno de ellos es el principio de buena fe, que está previsto en el artículo 7.1 del Código Civil y que, en materia 
de Derecho Administrativo es, si cabe, de mayor alcance que en el Derecho Privado. Por una razón elemental: porque para el Derecho Administrativo Constitucional, la Administración debe cumplir sus funciones en el marco del servicio objetivo al interés general. Esa objetividad, esa racionalidad, esa coherencia o congruencia que vincula la acción de la Administración reclama de ésta que actúe siempre en el marco de la buena fe. Buena fe de la que se deduce otro principio relevante del Derecho, hoy de gran actualidad en el Derecho Administrativo como es el principio de confianza legítima.

En segundo lugar, la evolución jurisprudencial del principio de buena fe demuestra hasta que punto ha sido fundamental la jurisprudencia contencioso administrativa en orden a la recepción en la legislación de estos principios. En este sentido puede afirmarse que así como el reconocimiento legal del principio de confianza legítima se debe a la jurisprudencia comunitaria, la carta de naturaleza legal del principio de la buena fe en el Derecho Administrativo es la consecuencia del sentido de la anticipación y de vanguardia que ha caracterizado, en este como en otros tema de todos conocidos, a la jurisprudencia contencioso administrativa española.

El principio de seguridad es, junto a la libertad y la justicia, uno de los tres criterios rectores que el preámbulo de la Constitución cita expresamente. Además, el artículo 9.3 de la Carta Magna lo incluye entre los principios jurídicos que la Constitución reconoce. Se trata de un principio básico del Estado de Derecho pues, en su virtud, el Ordenamiento jurídico es de aplicación a todos los operadores jurídicos, se reforma o modifica en atención a reglas conocidas y, fundamentalmente, dota al tráfico jurídico de un ambiente de estabilidad, certeza y previsibilidad que facilita la convivencia armónica y congruente.

En efecto, el Tribunal Supremo acaba de sentenciar el 14 de febrero de 2007 que el principio de confianza legítima, corolario necesario del principio de buena fe, "proporciona el marco de actuación de los particulares en sus relaciones con los poderes públicos administrativos se caracteriza por las notas de previsibilidad y seguridad jurídica, cuya normatividad en nuestro Ordenamiento jurídico subyace en las cláusulas del artículo 103 de la Constitución". Por sentencia de 24 de mayo de 1979, el Tribunal Supremo, en un caso de urbanismo en el que se discutía un problema de hechos consumados, no dudó en afirmar que uno de los principios inspiradores de esta realidad normativa el de estabilidad jurídica junto a la seguridad jurídica: "la ordenación del derecho de edificación debe realizarse de manera unitaria y coordinada a través de una meditada planificación que contemple de manera objetiva todos los intereses públicos y privados en juego y no mediante un acto aislado, inconexo o fragmentario que entraña una importante y grave modificación de una norma legal limitativa de aplicación general y autoriza fuera de ella una edificación singular que, como todas las de esta naturaleza, plantea importantes complejidades urbanísticas, deroga el principio de igualdad ante la ley, y los de estabilidad seguridad jurídicas de la ordenación urbanística"

La seguridad jurídica se refiere a la existencia de reglas ciertas de Derecho que contribuyan a que los operadores jurídicos sepan en todo momento a que atenerse. Es verdad que el principio de continuidad del Ordenamiento o el principio de conservación del Derecho son derivaciones del principio de seguridad jurídica. Sin embargo, una perspectiva dinámica del principio implica, como dispone la sentencia del Tribunal Supremo de 6 de octubre de 2000, que no se incluye derecho alguno a la inalterabilidad del régimen jurídico porque el principio de seguridad jurídica de acuerdo con la doctrina del Tribunal Constitucional sentada en sus sentencias 126/1987 y 182/1999 no supone la congelación o petrificación del Ordenamiento jurídico. En mi opinión, incluye la racionalidad y la objetividad, junto a la congruencia 
o coherencia de su reforma. Es decir, las modificaciones normativas han de realizarse de acuerdo con los procedimientos establecidos en las normas y atendiendo a circunstancias racionales y objetivas.

Un capítulo importante en esta materia es el que se refiere al principio de seguridad jurídica en el proceso de elaboración de las normas de naturaleza administrativa. Como principio general del Derecho que es, ha de informar todo el Ordenamiento, desde su nacimiento al mundo normativo hasta su aplicación o interpretación pasando por el proceso de confección o elaboración. En efecto, el propio Tribunal Constitucional ha señalado en su sentencia de 15 de marzo de 1990 que "el legislador ha de perseguir la claridad, no la confusión (...). Es relevante que los operadores jurídicos y los ciudadanos sepan a que atenerse en la relación con la materia sobre la que la ley legisla (...). Hay que buscar la certeza respecto a lo que es Derecho y no lo es y no provocar relaciones entre normas que den lugar a perplejidad respecto a la previsibilidad exigible al Derecho".

La doctrina que sienta el Tribunal Constitucional español en la sentencia citada permite extraer el contenido constitucional del principio de seguridad: que los operadores jurídicos y los ciudadanos sepan a que atenerse porque el Derecho, en sí mismo, ha de ser previsible. Es decir, si nos situamos en el campo del Derecho Administrativo, podríamos decir, desde esta perspectiva, que una derivación necesaria de la seguridad jurídica, a su vez del principio de la buena fe, es el principio denominado de confianza legítima. Se trata de un principio de naturaleza comunitaria, en cuya virtud resulta que la Administración pública no puede modificar unilateralmente el sentido de sus decisiones de no mediar una clara y concreta justificación que lo permita. Sólo excepcionalmente, y de manera motivada, la Administración pública puede cambiar el sentido de su actuación. Lo normal será que, en efecto, la actuación administrativa siga los cánones de la continuidad de las políticas públicas o, lo que es lo mismo, que actúe de acuerdo con la objetividad, imparcialidad y congruencia propia de quien está al servicio del interés general.

El Tribunal Supremo, por sentencia de 4 de junio de 2001, estableció que "el principio de confianza legítima, relacionado con los más tradicionales, en nuestro Ordenamiento de seguridad jurídica y buena fe en la relaciones entre la Administración y los particulares, comporta, según la doctrina del TJCE y la jurisprudencia de esta sala, el que la autoridad pública no pueda adoptar medidas que resulten contrarias a la esperanza inducida por la razonable estabilidad de las decisiones de aquélla, y en función de las cuales los particulares han adoptado determinadas decisiones". Es decir, la racionalidad, congruencia y objetividad, otros tantos principios generales de aplicación al Derecho Administrativo conducen a exigir a la Administración una actuación acorde con las expectativas o esperanzas que ha despertado en los particulares. De lo contrario, se quebraría el principio de buena fe, el de seguridad jurídica y el de confianza legítima. El Tribunal Supremo español entiende que la doctrina de la aplicación directa de los principios generales, entre ellos el de confianza legítima podría "anular un acto de la Administración o el reconocimiento de la obligación de ésta de responder de la alteración (sin conocimiento anticipado, sin medidas transitorias suficientes para que los sujetos puedan acomodar su conducta y proporcionadas al interés público en juego, y sin las debidas medidas correctoras o compensatorias) de las circunstancias habituales y estables, generadoras de esperanzas fundadas de mantenimiento".

El Tribunal Supremo del reino de España, pues, ha construido, a golpe de sentencias, el régimen de este principio señalando algunas condiciones y características necesarias para que se aplique. Las alteraciones normativas han de ser previamente conocidas por los desti- 
natarios naturales de la norma en cuestión, han de respetar los derechos adquiridos a partir de un razonable sistema de disposiciones transitorias y deben producirse en un marco de servicio objetivo al interés general. Obviamente, la confianza legítima, como antes señalamos, no implica, ni mucho menos, la inalterabilidad del Ordenamiento. La petrificación o congelación del Ordenamiento nada tiene que ver con la confianza legítima como a veces se pretende argumentar. De alguna manera, esta sentencia del Tribunal Supremo parece entreverlo cuando señala que " no pueden apreciarse los necesarios presupuestos de la aplicación del principio invocado en la mera expectativa de una invariabilidad de las circunstancias, y que ni el principio de seguridad jurídica ni el de confianza legítima garantizan que las situaciones de ventaja económica deban mantenerse indefinidamente estables, coartando la potestad de los poderes públicos para establecer nuevas regulaciones o para adoptar nuevos acuerdos".

El principio de seguridad jurídica exige que las normas sean claras, precisamente para que los operadores jurídicos sepan a que atenerse. Cuándo se fomenta la confusión, cuándo se oscurece el régimen jurídico deliberadamente o se incluyen en la parte final de la norma disposiciones más bien propias del título preliminar o del preámbulo, de alguna manera se está afectando negativamente al criterio jurídico de la seguridad jurídica, medida que nos da la intensidad y autenticidad del Estado de Derecho en cada país, en cada sistema jurídico.

En España tenemos que considerar un factor que complica la tarea. Me refiero a la pluralidad de centros de producción normativa que ha traído consigo la descentralización política alumbrada en la Constitución de 1978. Ahora tenemos numerosos Parlamentos y Gobiernos que producen leyes y normas administrativas. Se han multiplicado, pues, los centros de producción normativa y, por ende, las normas jurídicas. Además, coexisten diferentes grados e intensidades de intervención normativa sobre una misma materia en función de la naturaleza de la competencia que se tenga, que puede ser compartida o concurrente en muchos casos.

En este contexto, también debemos tener presente que la racionalidad política domina la racionalidad jurídica y normativa y que tantas veces el Derecho es reducido, nunca mejor escrito, a mera forma, a seguimiento de unos cauces procedimentales y poco más. Así, llegamos a un fenómeno hoy sorprendentemente frecuente: el uso alternativo del Derecho que, para el tema que nos ocupa en este momento, podríamos denominar uso alternativo de la técnica normativa. Es decir, las reglas que la racionalidad y el buen sentido jurídico dictan para la elaboración de las normas están al servicio del poder. Así se explica, por ejemplo, que los criterios, las directrices de técnica normativa, por ejemplo, todavía no dispongan de eficacia jurídica.

BIBLIOGRAFÍA

F. CASTILLO BLANCO, La protección de la confianza en el Derecho Administrativo, Madrid, 1998.

M.F. CLAVERO AREVALO, "La doctrina de los principios generales del Derecho y las lagunas del ordenamiento administrativo", RAP, nº 7, p. 51 y ss.

E. GARCIA DE ENTERRIA, "Reflexiones sobre la ley y los principios generales del Derecho", RAP, no 40, p. 189 y ss. 
J. GONZÁLEZ PÉREZ, El principio general de buena fe en el Derecho administrativo, Madrid, 1999.

J. DE LA CRUZ FERRER, "La elaboración y desarrollo de la teoría de los principios generales en el derecho público francés”, RAP, nº 111, p. 441 y ss.

J. LEGUINA VILLA, "Principios generales del Derecho y Constitución”, RAP, n 114, p. 7 y ss.

J. ARCE Y FLOREZ-VALDÉS, Los principios generales del Derecho y su formulación constitucional, Madrid, 1990.

M. BELADIEZ ROJO, Los principios jurídicos, Madrid, 1994.

J. SUAY RINCÓN, La doctrina de los principios generales del Derecho y su contribución al desarrollo del Derecho administrativo, Homenaje al profesor González Pérez, I, p. 379 y ss.

L. ORTEGA ÁLVAREZ, La funcionalidad y eficacia de los principios generales del Derecho, Justicia Administrativa, 15, pp. 52 y ss.

Cuadernos de Derecho público, $n^{\circ}$ 28, Monográfico sobre seguridad jurídica y aplicación del Derecho. 